\title{
PREVALÊNCIA DE DISFONIA EM PROFESSORES DO ENSINO PÚBLICO ESTADUAL AFASTADOS DE SALA DE AULA
}

\section{Prevalence of vocal dysfunction in teachers from the state education, licensed from classroom}

\author{
Lucia Cristina Fernandes Antunes Provenzano ${ }^{(1)}$, Tânia Maria Marinho Sampaio (2)
}

\begin{abstract}
RESUMO
Objetivo: identificar a prevalência da disfonia, gerando afastamento de sala de aula, em docentes do Ensino Médio da Rede Estadual de Educação. Métodos: foi realizado um levantamento exploratório de prontuários médicos de professores afastados de sala de aula, durante os anos de 2005 e 2006 , registrados na Superintendência Central de Perícias Médicas e Saúde Ocupacional do Estado do Rio de Janeiro. De uma amostra total de 554 professores lecionando durante o período analisado, foram pesquisados 130 prontuários de docentes licenciados por diversos diagnósticos, procurandose identificar os afastamentos com diagnóstico médico de disfonia. Resultados: evidenciou-se que, apesar das elevadas taxas de prevalência de sinais e sintomas vocais negativos entre os professores relatados em outras pesquisas, apenas $6,9 \%$ afastaram-se de sala de aula por disfonia. Os resultados possibilitam, ainda, reflexões acerca da relação existente entre voz, corpo, respiração e emoção, no contexto da docência. Conclusão: conclui-se que mesmo a disfonia sendo um problema frequente no trabalho docente, pouco se conhece sobre os dados oficiais de professores afastados de sala de aula por esse comprometimento. Torna-se necessário maior número de pesquisas para que os responsáveis por decisões políticas, sejam alertados e sensibilizados quanto à importância do assunto, em termos sociais e econômicos para o País. Ressalta-se a necessidade de que o trabalho fonoaudiológico desenvolvido com os professores tenha cunho transdisciplinar, e que, de forma intersetorial e harmônica, programas e políticas de prevenção e promoção da saúde vocal possam ser oferecidos à classe docente.
\end{abstract}

DESCRITORES: Voz; Distúrbios da Voz; Educação

\section{INTRODUÇÃO}

Os professores estão entre os profissionais que têm na comunicação elemento vital para a viabilização de seu trabalho, sendo a voz o instrumento utilizado para estabelecer vínculos diretos com o aluno, a família e a comunidade ${ }^{1,2}$.

Estudos apontam que distúrbios vocais podem ser mais frequentes entre a população que

(1) Fonoaudióloga da Fundação de Apoio à Escola Técnica do Estado do Rio de Janeiro, FAETEC, Rio de Janeiro, RJ, Brasil; Mestre em Fonoaudiologia pela Universidade Veiga de Almeida.

(2) Graduação em Letras pela Universidade Federal do Rio de Janeiro; Professora da Universidade Veiga de Almeida, UVA, Rio de Janeiro, RJ, Brasil; Professora da Universidade Federal Fluminense, UFF, Niterói, RJ, Brasil; Doutora em Filosofia pela Universidade Gama Filho.

Conflito de interesses: inexistente necessita utilizar a voz profissionalmente, devido à grande demanda vocal e exposição aos diversos fatores de risco. Voz profissional foi conceituada como uma forma de comunicação oral, utilizada por indivíduos que dela dependem para exercer sua atividade ocupacional e, por meio desse modo de expressão, atingir um público específico e determinado ${ }^{3-7}$. Dentre os distúrbios da comunicação, há os distúrbios vocais que são denominados disfonias, sendo caracterizados como qualquer dificuldade na emissão da voz, que podem impedir a transmissão da mensagem verbal e/ou emocional do discurso ${ }^{8}$.

A prevalência da disfonia na docência tem despertado o interesse entre os fonoaudiólogos, na tentativa de melhor compreensão sobre o problema de voz que se evidenciou na clínica fonoaudiológica, como também, devido à relevância social do problema. Tal prevalência é determinada na maior 
parte dos estudos, pelo número de sinais e sintomas vocais relatados pelos professores, sendo mensurada, frequentemente, por meio de questionários auto-aplicados, e analisando em maior número, os professores da Educação Infantil e Fundamental ${ }^{9-11}$. Na prática, as medidas de prevalência são utilizadas na ciência epidemiológica. Se entendermos que a epidemiologia tem como objetivo geral contribuir para diminuir os problemas de saúde na população, um caminho para se alcançar tal objetivo é representado pelo melhor conhecimento da distribuição das doenças, dos fatores que determinam essa distribuição, como também das possibilidades de êxito relacionadas às intervenções destinadas à alteração desse quadro patológico. Um dos princípios básicos dessa ciência é o de que os agravos à saúde não ocorrem ao acaso na população ${ }^{12}$.

Refletindo sob esse ponto de vista, pode-se pensar que os distúrbios de voz dos professores são consequências da ação de fatores que se encontram distribuídos em alguns elementos dessa população, sendo exemplos de fatores as condições ambientais e organizacionais em que a docência é exercida, e a falta de conhecimentos de técnicas e cuidados especiais com a saúde vocal. A descoberta desses fatores de risco permite que se atue em prevenção e tratamento desses distúrbios, como também em alvos específicos, tendo como resultado um aumento na eficácia das intervenções ${ }^{13-16}$.

Estudos nacionais e internacionais que investigaram por meio de questionários a prevalência de alteração vocal e de alteração vocal auto-referida, em professores de diferentes níveis de ensino, concluíram que tal prevalência é elevada, variando de 21 a $80 \%{ }^{3,4,9,11}$. Diversas pesquisas que utilizaram informações dos próprios professores, obtidas também por meio de questionários, foram realizadas com docentes em vários estados do Brasil, e tiveram como resultado uma porcentagem que variou de $54 \%$ a $79 \%$ de queixas relacionadas à voz ${ }^{17-19}$. A alta ocorrência de problemas de voz entre os professores, de uma forma geral demonstra que essa profissão pode estar demandando cuidados relevantes direcionados à voz. A necessidade de maior conhecimento do que está acontecendo, passa a ser então um foco de estudo importante.

Apesar da atenção dispensada nos últimos anos à voz do professor, algo parece estar faltando para a real eficiência desse trabalho. Tal fato deve ocorrer porque, raramente, um problema vocal incida sobre uma única causa, sendo seu exame e tratamento complexos. Deve-se ter a visão holística que, pressupondo em si estudos transdisciplinares no processo saúde/doença, requer ações conjuntas ou integradas dos profissionais, instituições e sociedade, permitindo a introdução de novos elementos nesse processo.

Identificar a prevalência de distúrbios vocais entre os professores, que ocasionem afastamento de suas atividades profissionais é um caminho a ser percorrido, a fim de se obter o conhecimento e a abrangência dessa problemática e da influência na saúde e na qualidade de vida dos docentes. O conhecimento produzido a partir dessa pesquisa sustenta a reflexão do procedimento fonoaudiológico no trabalho com os professores, possibilitando melhor qualidade de vida para esses profissionais.

$\mathrm{O}$ interesse pelo tema dessa pesquisa se deve, de uma certa forma inédita, pelo caminho metodológico, que não descartando os dados subjetivos dos questionários auto-aplicados, evidenciadores das percepções dos próprios professores, norteou-se, sobretudo, pela consulta do formulário médico ocupacional, viabilizando dados concretos da prevalência da disfonia. Tomando como referência a importância da voz no processo educacional, o objetivo desse estudo é identificar a prevalência de disfonia em professores do ensino médio público estadual afastados de sala de aula.

\section{MÉTODOS}

Este estudo é de caráter longitudinal e descritivo. O universo da amostra da pesquisa consistiu de professores do Ensino Médio, afastados de suas atividades profissionais, no período compreendido entre janeiro de 2005 e dezembro de 2006 inclusive. Foram selecionados para investigação professores afastados que pertenciam a duas unidades escolares da rede de uma Fundação de Ensino do Estado do Rio de Janeiro (FAETEC), que possui cursos de ensino básico, profissionalizante e superior. Do universo total de 2.764 professores, 1.570 trabalham no Ensino Médio. Do total, a maioria está lotada, principalmente, nas duas escolas selecionadas, perfazendo um total de 554 professores. A partir deste total de professores em atividade, selecionou-se a amostra de profissionais que efetivaram pedido oficial de afastamento e cujos processos estavam arquivados na Superintendência Central de Perícias Médicas e Saúde Ocupacional. A amostra total de afastados por motivos diversos era de 178 professores, dos quais 106 eram do sexo feminino, e 72 do sexo masculino.

Do total de 178 afastamentos, o acesso só foi possível a arquivos de 130 professores afastados, pois os restantes 48 encontravam-se nas seguintes situações:

1) Professores com acumulação lícita; caso em que a licença é tirada pela matrícula de maior 
tempo que pertence à Secretaria Estadual de Educação.

2) Professores com domicílio fora do Grande Rio; caso em que o afastamento é concedido pelas cidades em que residem.

Como instrumentos, foram utilizados os seguintes formulários:

- Relação funcional dos professores afastados por perícia médica, no período compreendido entre 2005 e 2006. Esse documento é fornecido pelo setor de recursos humanos da escola onde o professor leciona, contendo o seu nome, matrícula, cargo, carga horária, período de afastamento e número do BIM (boletim de inspeção médica), fornecido pelo setor de perícia médica.

- Prontuário médico ocupacional - Em forma de pasta, agrupa documentos que contém informações médico-administrativas sobre os professores, como também informações fornecidas pelo médico perito, a partir das quais, é concedido o tempo de afastamento do professor, com possibilidade de prorrogação dessa licença médica. O médico perito, para conceder tal licença, leva em consideração os relatórios médicos e exames complementares portados pelo professor.

- Laudo médico do otorrinolaringologista, com o diagnóstico do motivo do pedido da referida licença.

A primeira fase da pesquisa consistiu na utilização de uma carta de apresentação da pesquisadora com o tema e o objetivo, entregue nos locais em que o estudo se realizou. A carta visou à obtenção de uma parceria com os órgãos, seja quanto à permissão de utilização do espaço físico, seja quanto à obtenção dos dados referentes aos professores, pertencentes aos setores-alvo desse estudo. Em seguida, foi realizado o levantamento dos números identificadores das fichas funcionais dos professores das escolas selecionadas, que se encontravam afastados de suas atividades profissionais. A coleta de dados foi realizada junto ao Departamento de Recursos Humanos da escola onde o professor lecionava. A seleção desses números objetivou suprimir o nome do professor e manter a identificação dos participantes durante o processo de coleta de dados. Esse levantamento teve também por finalidade facilitar a busca e localização dos prontuários médico-ocupacionais, subsidiando a etapa seguinte da pesquisa.

De posse do número da ficha funcional do professor, foi iniciada a terceira etapa, a identificação do prontuário médico ocupacional, no momento realizado no setor de Superintendência Central de Perícias Médicas e Saúde Ocupacional, órgão que pertence à Secretaria Estadual de Saúde e Defesa Civil.
Foram analisados todos os prontuários, no período de março a junho de 2007, e a análise buscou identificar os pedidos de afastamento por disfonia. Os seguintes dados foram coletados em relação a cada professor: idade, sexo, carga horária, tempo de docência na Instituição pesquisada, diagnóstico médico, diagnóstico laringológico e tempo concedido de afastamento. Não foram levados em consideração relatos escritos de alteração vocal com licenças concedidas por diagnóstico médico de amigdalite, faringite e doenças do sistema respiratório. Há o reconhecimento da relação existente entre as infecções das vias aéreas superiores e os quadros de comprometimento vocal, porém, nesta pesquisa, optou-se pela não utilização desse critério. O motivo que levou a essa conduta foi justamente a observação da relação que foi dada entre o uso de voz profissional e doenças do sistema respiratório, valendo-se da importância e necessidade de que esse dado seja valorizado, observado, tanto pelo usuário do sistema de saúde, no caso específico, o professor, como também, pelo profissional que realiza a avaliação médica. Foram analisados mais profundamente os professores que obtiveram licença tendo como queixa o sintoma vocal e o diagnóstico médico de disfonia, com alterações laríngeas confirmadas através de exame de videolaringoscopia. Considera-se que os dados aqui obtidos é que permitiram identificar a prevalência da disfonia associada à alteração anatomofuncional da laringe, gerando afastamento em professores de ensino médio na educação pública estadual.

Com o objetivo de facilitar a localização dos prontuários, providenciou-se uma lista contendo os respectivos números em ordem crescente. Ao final, os números dos prontuários foram excluídos, resguardando-se a privacidade e o sigilo médico de cada professor. Os dados coletados foram organizados em uma planilha elaborada para tal fim, e analisados de maneira absoluta (numérica) e relativa (percentualmente).

Os diagnósticos médicos encontrados na perícia, por se tratar de área específica, são tecnicamente aceitos. São documentos que contêm informações sigilosas, tanto do ponto de vista médico, como do administrativo, logo, o seu acesso só foi permitido ao público externo, no caso a pesquisadora, com o acompanhamento de um funcionário colocado à sua disposição, para auxiliar na coleta de dados, bem como para garantir o seu sigilo. É válido registrar que essa conduta foi mantida nas duas Instituições, onde houve acesso à documentação necessária para a viabilização da pesquisa.

Esta pesquisa foi aprovada pelo Comitê de Ética e Pesquisa da Universidade Veiga de Almeida sob a resolução número 121/08. 
Os dados obtidos por meio da análise documental foram submetidos a um estudo descritivo com expressão em percentagens, considerando-se as faixas etárias, sexo, carga horária, tempo de docência, e as diversas causas de afastamento.

\section{RESULTADOS}

O quadro funcional das duas escolas pesquisadas era composto por 554 professores. Desse total, 178 solicitaram licença médica no período analisado, correspondendo a $32 \%$ da amostra (Figura 1).

Conforme os dados analisados se observa um universo de professores licenciados, em sua maioria do sexo feminino e com faixa etária de 36 a 55 anos, possuindo carga horária de 40 horas semanais e havendo maior predominância de professores em ambos os sexos com oito anos de docência na Instituição pesquisada (Figuras 2 e 3 e Tabela 1).

A pesquisa constatou que a maior frequência de afastamentos para professores de ambos os sexos deu-se por motivos osteomusculares; em segundo lugar, vêm os problemas respiratórios, seguidos pelos distúrbios psiquiátricos e por necessidade de acompanhamento de familiares doentes. $\mathrm{Na}$ quinta categoria, em termos de frequência, aparecem condições ginecológicas, restritas, portanto, ao sexo feminino. Somente em sexto lugar, é que se constata que o motivo de afastamento foi a disfonia associada à alteração anatomofuncional da laringe
(Figura 4). Os resultados, em ênfase, referem-se apenas a este diagnóstico.

Verifica-se que, do universo de professores licenciados, 6,9\% afastaram-se de sala de aula com diagnóstico médico de disfonia (Figura 5).

Com relação à caracterização dos professores afastados por disfonia (Tabela 2), os dados mostram a mesma frequência por alterações laríngeas. Foram encontrados três professores que apresentaram laudo de hiperemia, três com edema e três com fenda glótica. Em relação à carga horária, nota-se que a maior parte leciona 40 horas semanais, sendo que um docente possui carga horária de 60 horas, totalizando $78 \%$ da amostra pesquisada. Quanto aos dados de afastamento de sala de aula em relação ao sexo, evidenciou-se um grupo na sua maioria feminino, na faixa etária de 31 a 57 anos.

\section{DISCUSSÃO}

Os resultados identificaram a prevalência de 6,9\% de professores do Ensino Médio afastados de sala de aula, com disfonia associada à alteração anatomofuncional da laringe (Figura 5).

Comparando-se o resultado desse estudo com os resultados apresentados na literatura, observam-se dados contrastantes no que se refere a pesquisas fonoaudiológicas que identificaram tal prevalência em professores, utilizando como material metodológico o questionário auto-aplicado ${ }^{3,5,9,18}$. A diferença está ancorada em algumas questões que merecem reflexão e discussão.

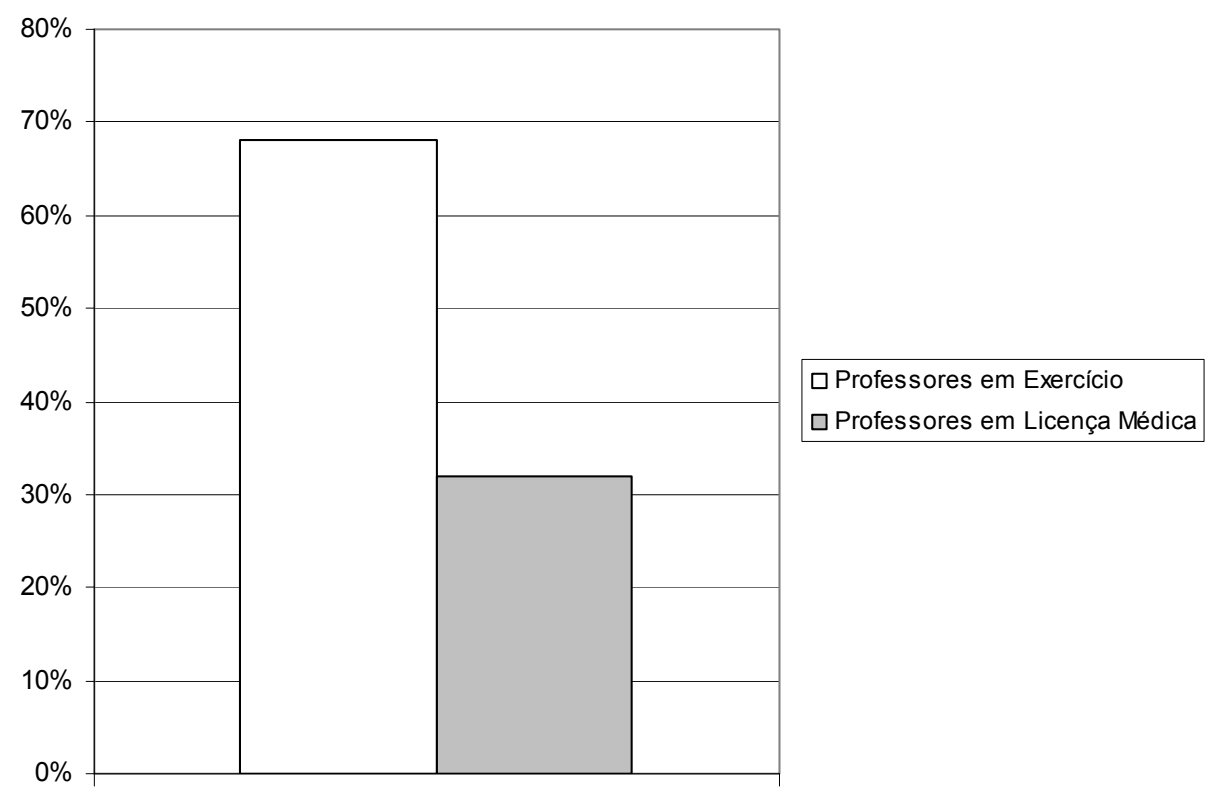

Figura 1 - Distribuição percentual dos professores afastados, quanto ao universo total 


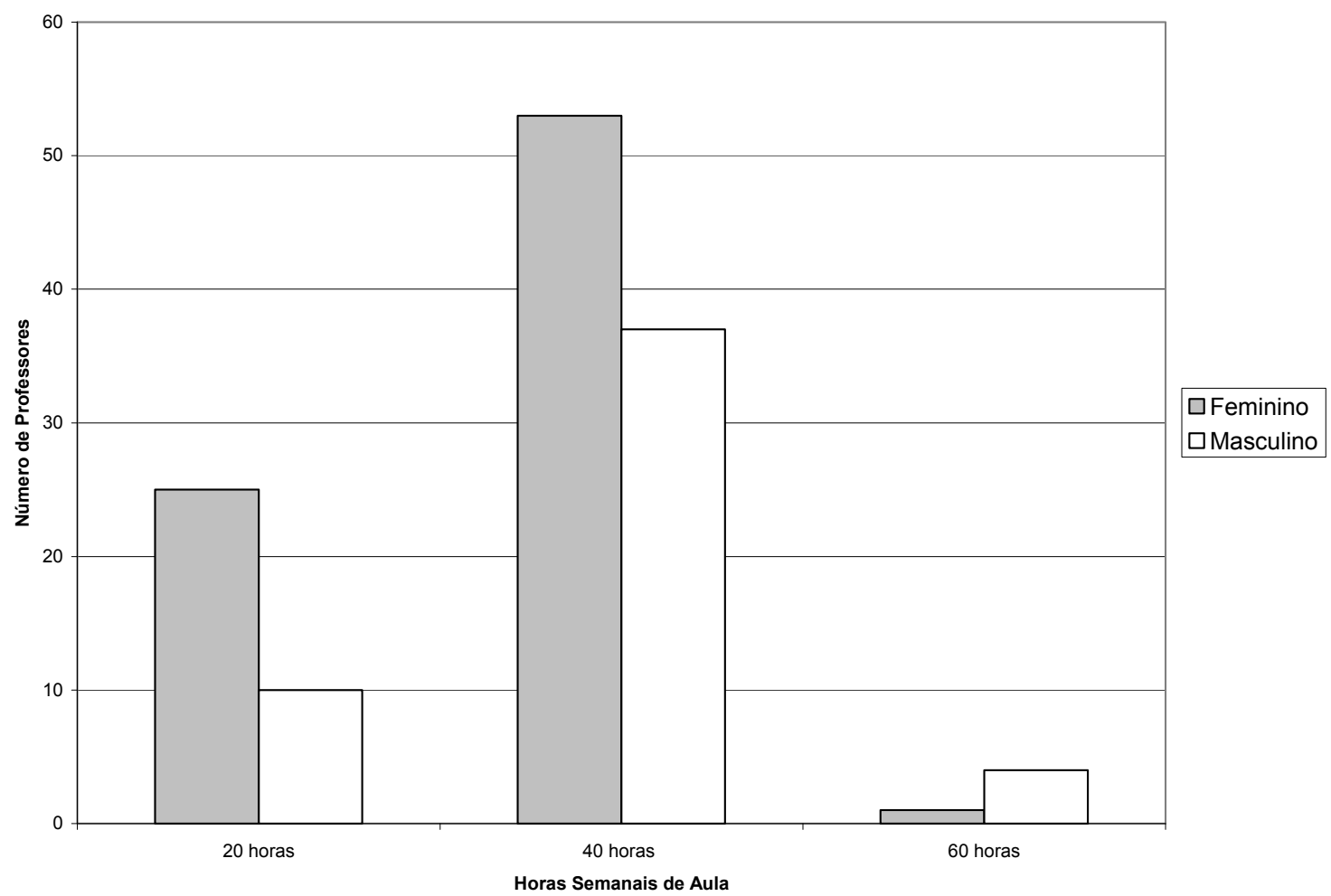

Figura 2 - Distribuição dos professores afastados quanto à carga horária

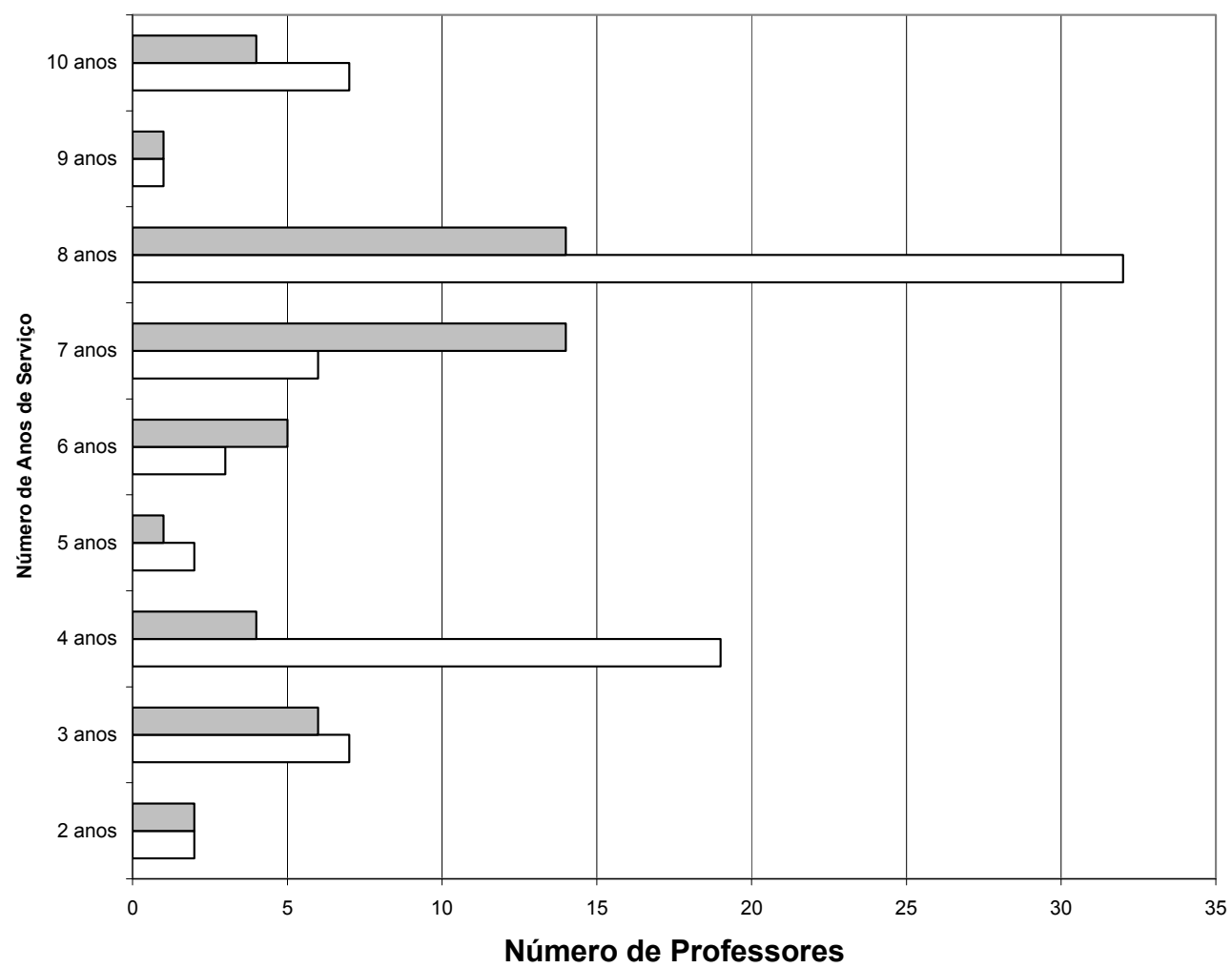

Figura 3 - Distribuição dos professores quanto ao tempo de docência na instituição 
Tabela 1 - Distribuição dos professores afastados quanto ao sexo e à idade

\begin{tabular}{ccccc}
\hline Idade & Feminino & Masculino & Total & Porcentagem (\%) \\
\hline $25-30$ & 1 & 2 & 3 & 2,31 \\
$30-35$ & 6 & 4 & 10 & 7,69 \\
$35-40$ & 15 & 11 & 26 & 20,00 \\
$40-45$ & 18 & 11 & 29 & 22,31 \\
$45-50$ & 15 & 8 & 23 & 17,69 \\
$50-55$ & 14 & 8 & 22 & 16,92 \\
$55-60$ & 8 & 4 & 12 & 9,23 \\
$60-65$ & 2 & 3 & 5 & 3,85 \\
Total & 79 & 51 & 130 & 100,00 \\
\hline
\end{tabular}

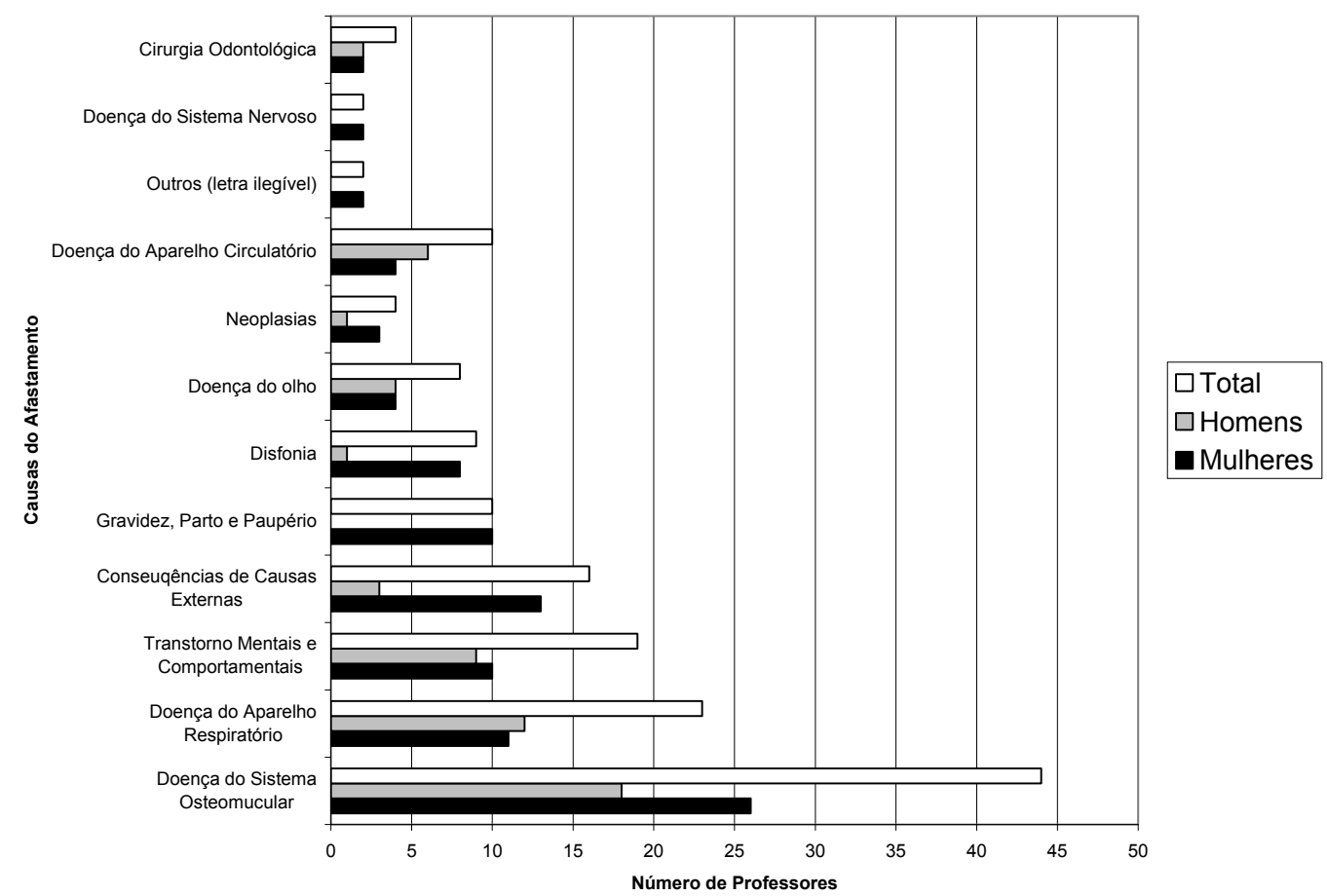

Figura 4 - Distribuição dos professores afastados e seus respectivos diagnósticos

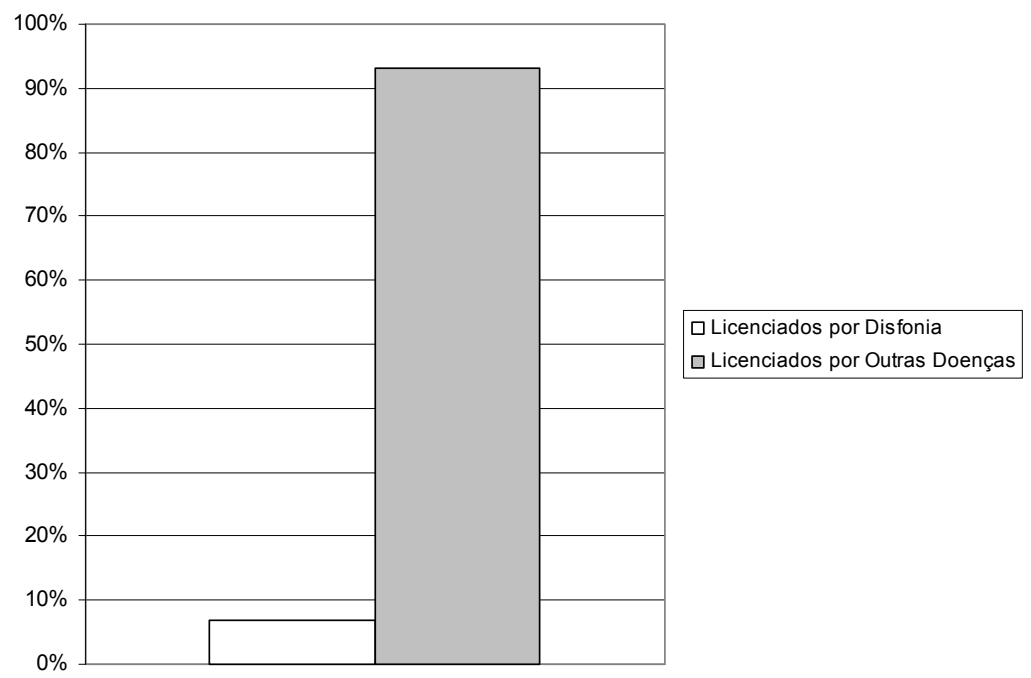

Figura 5 - Distribuição percentual dos professores afastados por disfonia 
Tabela 2 - Caracterização dos professores afastados por disfonia

\begin{tabular}{|c|c|c|c|c|c|}
\hline Sexo & $\begin{array}{l}\text { Idade } \\
\text { (anos) }\end{array}$ & $\begin{array}{c}\text { Carga } \\
\text { Horária } \\
\text { Semanal }\end{array}$ & $\begin{array}{c}\text { Tempo de } \\
\text { Serviço } \\
\text { (anos) }\end{array}$ & $\begin{array}{c}\text { Tempo de } \\
\text { Afastamento }\end{array}$ & $\begin{array}{l}\text { Diagnóstico } \\
\text { ORL }\end{array}$ \\
\hline Feminino & 31 & 40 & 4 & 8 dias & Hiperemia de prega vocal \\
\hline \multirow{4}{*}{ Feminino $\left({ }^{*}\right)$} & \multirow{4}{*}{32} & \multirow{4}{*}{40} & \multirow{4}{*}{10} & 11dias & \multirow{4}{*}{ - Edema de prega vocal } \\
\hline & & & & 10 dias & \\
\hline & & & & 10 dias & \\
\hline & & & & 10 dias & \\
\hline Feminino $\left({ }^{* *}\right)$ & 42 & 40 & 8 & 7 meses & $\begin{array}{l}\text { Fenda glótica em } \\
\text { ampulheta e Nódulo de } \\
\text { prega vocal esquerda }\end{array}$ \\
\hline Feminino $\left({ }^{\star \star \star}\right)$ & 43 & 60 & 8 & 7 meses & $\begin{array}{l}\text { Fenda glótica dupla e } \\
\text { nódulos }\end{array}$ \\
\hline Masculino & 46 & 40 & 8 & 8 dias & Hiperemia de prega vocal \\
\hline Feminino & 47 & 20 & 3 & 15 dias & Edema de prega vocal \\
\hline Feminino & 52 & 20 & 10 & 10 dias & Edema de prega vocal \\
\hline Feminino $\left({ }^{* \star *}\right)$ & 53 & 40 & 10 & 6 meses & $\begin{array}{l}\text { Fenda glótica em } \\
\text { ampulheta e cisto de } \\
\text { prega vocal esquerda }\end{array}$ \\
\hline Feminino & 57 & 40 & 7 & 7 dias & Hiperemia de prega vocal \\
\hline
\end{tabular}

(*) A professora obteve quatro licenças intercaladas, no período analisado, sendo uma no ano de 2005 e três em 2006 . Não há relato em seu prontuário de tratamento fonoaudiológico.

$\left.{ }^{(*}\right)$ O tempo de afastamento consta desde a concessão da primeira licença médica, até o período analisado nesta pesquisa. A professora encontra-se no momento readaptada por um ano, com publicação no Diário Oficial de 21 de dezembro de 2006. A solicitação da readaptação foi realizada por uma fonoaudióloga.

$\left.{ }^{* \star *}\right)$ O tempo de afastamento consta desde a concessão da primeira licença médica, até o período analisado nesta pesquisa. A professora foi readaptada por seis meses, com publicação no Diário Oficial de 30 de março de 2007.

${ }^{\left.{ }^{\star * * *}\right)}$ O tempo de afastamento consta desde a concessão da primeira licença médica, até o período analisado nesta pesquisa. Há relato de uma solicitação de licença negada. A professora encontra-se, no momento, readaptada por um ano, com publicação no Diário Oficial de 16 de março de 2007.

Embora pesquisas anteriores ${ }^{14,19-22}$ evidenciem alta prevalência de professores com disfonia, relatando alterações vocais associadas ao trabalho, foi demonstrado que este fato não contribui de forma significativa para gerar o afastamento do professor de sala de aula.

Estimava-se um número maior de professores com necessidade de licenças, devido ao elevado número de educadores relatando queixas vocais, não apenas nas séries de ensino iniciais, mas também em níveis de ensino médio e superior ${ }^{23,24}$. Vale lembrar que a presente pesquisa foi realizada com profissionais do setor público, com estabilidade formal de trabalho, o que não os vulnerabiliza frente a um afastamento por doença. De acordo com o Decreto Estadual número 2479/1979, que aprova o Regulamento do Estatuto dos Funcionários Públicos Civis do Poder Executivo do Estado do Rio de Janeiro, em seu artigo 116, a licença para tratamento de saúde será concedida sempre com vencimento integral ${ }^{25}$.
Os índices de afastamentos encontrados ratificam estudos internacionais ${ }^{3,26}$ e brasileiros ${ }^{24-27}$ realizados com docentes do serviço público e particular. Tais pesquisas argumentam que o professor permanece lecionando, mesmo na presença de uma voz alterada.

Estudiosos americanos constataram que $43 \%$ de professores apresentaram múltiplos sinais e sintomas vocais atribuídos a sua ocupação. Os pesquisadores atentam para o fato de mais de um terço dos professores referirem que sua voz não possuía mais o mesmo desempenho, e nem era como gostariam que fosse, e mesmo nessas condições, a maioria dos professores não procurou ajuda nem solicitou licença para tratamento, fato confirmado por pesquisadores brasileiros ao constatarem em seu levantamento, que $60 \%$ de professores referiram apresentar problema vocal, e quando perguntados se haviam realizado tratamento especializado, $61,4 \%$ afirmaram que não ${ }^{3-18}$. $O$ fato de que 0 professor não percebe o início de sua problemática 
vocal e continua a lecionar normalmente, até que a voz comece a piorar de forma drástica, é observado por pesquisadores brasileiros e estrangeiros. Os estudiosos acreditam que o professor permanece lecionando, apresentando sua voz alterada, sem buscar auxílio profissional, por diversos motivos; entre eles, questões financeiras, como também, o fato de ser essa uma profissão onde há uma grande tolerância em falar apesar de um comprometimento vocal, o que aponta para uma tendência do professor de minimizar o problema de voz ${ }^{20-22}$.

Sob essa ótica, pode ser que os profissionais da Educação preocupem-se mais com a funcionalidade da voz, e não com a qualidade de sua voz. Nesse caso, há uma tendência para que o professor não considere a disfonia como risco ocupacional, julgando que os problemas de voz sejam inerentes à docência, não considerando a necessidade de prevenir ou tratar o problema, que passa a ser vista como uma consequência natural da profissão. O professor precisa se conscientizar de que seus problemas de voz podem ser relacionados ao seu trabalho, sendo um direito seu orientações prévias, periódicas e possível tratamento. O não reconhecimento do professor com relação a esse direito é corroborado em um estudo brasileiro ${ }^{28}$, no qual observou-se que o professor não realiza a interpretação da saúde como um direito social.

Por outro lado, acredita-se que a remuneração salarial dos profissionais da Educação, e a realidade da saúde em nosso país somam-se aos motivos que dificultam ao professor a busca de ajuda especializada. A dificuldade encontrada para que se consiga atendimento fonoaudiológico na rede pública não pode ser esquecida, e ocorre pelo quantitativo insuficiente de profissionais no atendimento à população de uma forma geral. Torna-se necessário, que um programa de saúde vocal do professor seja implementado na Rede Estadual de Ensino do Rio de Janeiro, a exemplo do que ocorre na Rede Municipal. A implantação de políticas públicas de promoção da saúde vocal dos professores deve ser pautada em processos educativos de caráter processual, com o objetivo de prestar melhor assistência a esses profissionais.

Os resultados da presente pesquisa encontram respaldo em trabalhos que mostraram ser baixa a influência dos problemas vocais no desempenho profissional 24-29. Esses estudos indicaram que, na percepção da maioria dos professores, houve dificuldade em perceber e valorizar os sintomas vocais como indicativos de problemas, e de identificar a saúde vocal como componente da saúde geral. Identificou-se licenças concedidas por disfonia associada à alteração anatomofuncional da laringe aos professores na razão de 6,9\%, resultado equivalente ao encontrado por pesquisadoras em Brasília. As pesquisadoras da Universidade de Brasília observaram que, enquanto foram concedidos $33,3 \%$ dos afastamentos por problemas de voz entre os bancários e $16,7 \%$ entre os profissionais de rádio e TV foram considerados como relacionados ao trabalho, entre os professores a taxa foi de apenas $6,4 \%{ }^{30}$. Pesquisas que também abordaram licenças de saúde para professores 28,31,32 identificaram como maior causa de afastamento as doenças do sistema respiratório, em que se incluem as disfonias, enquanto constatou-se que as alterações do sistema respiratório se fizeram a segunda maior causa de absenteísmo (Figura 4).

Neste estudo verificou-se a prevalência da disfonia, não realizando associação entre o relato escrito de alteração vocal e licença concedida por diagnóstico médico de faringite, amigdalite e comprometimento do sistema respiratório, uma vez que a pesquisa se valeu do sintoma que levou o professor à solicitação da licença, no caso específico a disfonia, confirmado por dado objetivo, através da solicitação médica do exame laríngeo.

Tem-se o conhecimento da relação existente entre voz e algumas doenças do organismo, como por exemplo, as que pertencem ao sistema respiratório. Quando a pessoa faz uso da voz de forma profissional, essa relação torna-se mais estreita ${ }^{5,8}$. Apoiando tal hipótese, professores que, nesse estudo, obtiveram licenças concedidas por doenças do aparelho respiratório, poderiam ter algum distúrbio vocal associado, o que aumentaria a taxa de prevalência encontrada. Nesse sentido, nota-se a importância e a necessidade da abordagem de uma equipe com conduta transdisciplinar, formada por profissionais da área da saúde, entre eles, o fonoaudiólogo, o médico do trabalho e o otorrinolaringologista, para que se obtenha uma leitura global do comprometimento vocal do professor, realizando as relações e orientações necessárias, objetivando dessa maneira, a saúde vocal do professor.

Etimologicamente, o prefixo trans significa aquilo que está ao mesmo tempo entre as disciplinas, através das disciplinas e além de toda disciplina. Propõe-se a integração das diversas áreas do conhecimento com o atravessamento das especialidades, a migração dos conhecimentos e o desenvolvimento coeso do conhecimento ${ }^{33}$.

A visão transdisciplinar na atenção aos problemas de voz do professor deve ocorrer desde o processo de admissão, avaliação e diagnóstico, incluindo os programas de prevenção e promoção da saúde vocal, para que se possa realizar a interpretação dos sinais e sintomas relacionados ao uso da voz, como também propiciar uma análise dos 
fatores predisponentes, agravantes e consequentes da disfonia.

A compreensão da transdisciplinaridade, englobando os aspectos físicos, biológicos, afetivos, sociais e relacionais, leva à reflexão sobre quantos desses aspectos condizem com o trabalho fonoaudiológico em relação ao professor. Identificar essa atitude enquanto movimento de práxis não é fácil, porém é fundamental que os cursos de formação abram espaço para esta dimensão, sendo importante que os profissionais que lidam com pessoas sejam formados dentro dessa perspectiva. Saber ouvir, saber dialogar não é apenas um adendo na formação, mas, sim uma competência profissional essencial na prática, possibilitando que a demanda do usuário, no caso específico o professor, seja levada em consideração.

É, assim, a transdisciplinaridade que pressupõe uma quebra de paradigma, com a perspectiva de um novo pensar sobre a conduta fonoaudiológica, frente ao comprometimento vocal do professor. Pode-se então identificar o que se deseja alcançar em relação à introdução do real significado de valor do trabalho fonoaudiológico nas escolas, provocando efetivas modificações em relação ao envolvimento e conscientização do professor.

Em relação aos dados referentes ao afastamento do professor (Tabela 2), as possíveis correlações foram realizadas face às informações obtidas em seu prontuário médico-ocupacional, porém, a definição exata de cada fator de afastamento e sua carga de responsabilidade depende do cruzamento com outras questões, como por exemplo, a problemática do ensino de um modo geral, diferenças individuais e condições do exercício profissional. Constata-se que os professores, em sua maioria, obtiveram tempo de afastamento de sete a quinze dias, sem constar em seus prontuários orientação para a procura de tratamento fonoaudiológico. A licença temporária obtida dessa maneira significa que o professor foi atendido por um serviço de saúde, com ação sintomática e pontual, em relação ao seu comprometimento.

Um aspecto que necessita ser salientado nesse modelo de atendimento é o fato de o professor retornar às suas atividades, sem maior conhecimento do que pode estar prejudicando a sua saúde vocal, com riscos de recidiva ou agravamento do comprometimento inicialmente apresentado. Dessa maneira, os afastamentos dos professores, por licenças médicas temporárias, nem sempre garantem o regresso ao trabalho com sucesso, em relação à saúde, e conscientização das necessárias mudanças em seu ambiente de trabalho.

No tocante à carga horária dos professores licenciados, nota-se que a maior parte leciona 40 horas semanais, sendo que um docente possui carga horária de 60 horas, totalizando $78 \%$ da amostra pesquisada com maior demanda vocal (Figura 3). Estudos relatam que uma das explicações para a ocorrência da disfonia em professores pode ser a elevada demanda vocal da profissão ${ }^{4,11,30}$. Questiona-se, porém, que a disfonia desses professores não possa ser causada apenas pela demanda vocal, mas sim, associada à utilização da voz em alta intensidade, sem técnica adequada, por longos períodos, sem possibilidade de tempo para repouso da musculatura vocal, gerando fadiga vocal e podendo contribuir para o aparecimento de alterações laríngeas $3,13,27,34$.

A disfonia compreendida como multifatorial admite que estejam presentes fatores de ordem postural, respiratória e emocional. Neste trabalho, foram discutidos apenas os afastamentos por disfonia. Porém, há que se levar em consideração o índice de problemas categorizados como oesteomusculares, bem como os respiratórios e os emocionais, sendo as três maiores frequências de afastamentos de professores, causas também observadas em pesquisas que abordaram licenças de saúde para professores ${ }^{28,31,32}$. Essas três causas podem estar relacionadas às condições de trabalho do professor. Na condição postural, onde os professores mantêm-se em pé por longo período, ou sentados em mobiliários incompatíveis ao corpo físico, expostos ainda a condições inóspitas em relação a resíduos de giz, poeira, mofo, umidade, condições essas que afetam o sistema respiratório e, agravado sobretudo o quadro somando-se o sentido emocional, na ordem do estresse, contribuindo para a tensão muscular, situações estas que dificultam uma emissão vocal adequada (Figura 4).

Retirando o foco especificamente do comprometimento vocal, o viés aqui apontado que atribui a presente pesquisa um sentido de singularidade, faz-se na orientação da integração corpo-voz no contexto da abordagem fonoaudiológica realizada com o professor. Com essa conduta, obtém-se um reolhar no tocante à abertura de um leque de possibilidades, norteando valores que parecem fundamentais na percepção dos problemas de voz do professor.

Quanto ao número de professores licenciados e o laudo do exame otorrinolaringológico, observa-se que grande parte do grupo pesquisado caracteriza um quadro de alteração secundário com relação à disfonia funcional (Tabela 2), evidenciando a necessidade de programas de auto-conhecimento e treinamento vocal.

Quanto aos dados de afastamento de sala de aula em relação ao sexo (Tabela 2), evidenciou-se um grupo na sua maioria feminino, na faixa etária de 
31 a 57 anos. Ao longo de sua história, o magistério tornou-se uma carreira exercida por um número expressivo de mulheres. Estudiosos, que realizaram revisão de literatura de pesquisas envolvendo professores do ensino fundamental, médio e superior, de ambos os sexos, observaram prevalência de alteração vocal auto-referida mais baixa do que nos estudos que envolviam apenas professoras, obtendo uma taxa que variou de 31 a $75 \%$. Os autores relacionaram esse achado ao fato de a pesquisa contar com a participação dos gêneros masculino e feminino, lembrando que, devido a características fisiológicas e de configuração laríngea, as mulheres apresentam maior risco para esse comprometimento, quando comparadas aos homens. Apesar de as pesquisas terem sido realizadas por meio de questionários auto-aplicados, o que diferencia o caminho metodológico deste estudo, observase resultados não condizentes com os achados na presente pesquisa.

Dentre os diversos estudos sobre a voz do professor, destaca-se o estudo exploratório realizado por pesquisadores australianos. Os autores concluíram que a verdadeira prevalência de problemas vocais entre professores não é clara, por diversos fatores como, por exemplo, coleta de informações não-oficiais, e a utilização de autoquestionários, que em sua maior parte refletem dados subjetivos ${ }^{10}$.

Não é o objetivo, neste trabalho, desconsiderar os importantes resultados obtidos por meio do inquérito de questionários sobre a alteração vocal do professor. Através desse instrumento de pesquisa, focaliza-se a percepção dos próprios professores sobre as alterações no decorrer do tempo. Pretende-se, no entanto, que este estudo some-se a todos os outros já definidos e pesquisados, uma vez que contribui com dados objetivos e importantes para o diagnóstico da classe docente, em relação à prevalência da disfonia que causa afastamento de sala de aula, abrindo possibilidades para novos focos de análise com o intuito de apreender mais detalhadamente a representação desse afastamento.

\section{CONCLUSÃO}

Esta pesquisa constatou que, apesar de estudos anteriores evidenciarem altas taxas de professores relatando alterações vocais, apenas 6,9\% de professores afastaram-se de sala de aula com diagnóstico médico de disfonia associada à alteração anatomofuncional da laringe. Os resultados indicam a necessidade da realização de um maior número de pesquisas abordando o afastamento de docentes das atividades profissionais, por apresentarem comprometimento vocal. Este é um caminho para que os responsáveis por decisões políticas e/ ou administrativas educacionais sejam alertados e sensibilizados quanto à importância do assunto, em termos sociais e econômicos para o País.

\begin{abstract}
Purpose: to identify the prevalence of the vocal dysfunction which caused medical leave among high school teachers from the "State Education System". Methods: a survey was conducted analyzing school teachers' medical reports who were licensed for medical leave in 2005 and 2006 which were registered in the "Central Superintendence of Medical Expert Reports and Occupational Health of the State of Rio de Janeiro". From 554 school working teachers in the above-mentioned period, 130 medical reports were analyzed and on a leave because of several vocal dysfunctions diagnostics, trying to identify the medical leaves arising from vocal dysfunction. Results: it was clear that despite of the high prevalence rate of the negative vocal sign symptoms among school teachers, just $6.9 \%$ were on a leave due to vocal dysfunction. The results also allow for reflections on the relation amongst voice, body, breathing and emotion in the teaching world. Conclusion: it may be concluded that even when dysphonia usually a problem in the educational work, we know very little on official data concerning teachers who are licensed for medical leave. More research is required for the ones who are responsible for policy decisions, to be aware and sensible to the importance of the issue, for the country, in social and economics terms. We emphasize the need for speech therapist work development among school teachers to be a multidisciplinary job, with prevention programs and policies that are very important to implement and also to promote vocal health programs that may be offered to school teachers.
\end{abstract}

KEYWORDS: Voice; Voice Disorders; Education 


\section{REFERÊNCIAS}

1. Dragone MLS, Behlau M. A Fonoaudiologia brasileira e a voz do professor olhares científicos no decorrer do tempo. Fonoaudiol Bras. 2006; 4(2):6-9. 2. Penteado RZ. Relações entre saúde e trabalho docente: percepções de professores sobre saúde vocal. Rev Soc Bras Fonoaudiol. 2007; 12(1):18-22. 3. Roy N, Merril RM, Thibeault S, Gray SD, Smith EM. Voice disorders in teachers and the general population: effects on work performance, attendance, and future career choices. J Speech Lang Hear Res. 2004; 47(3):542-51.

4. Fortes FSG, Imamura R, Tsuji DH, Sennes LU. Perfil dos profissionais da voz com queixas vocais atendidos em um centro terciário de saúde. Rev. Bras. Otorrinolaringol. 2007; 73(1):27-31.

5. Fuess VLR, Lorenz MC. Disfonia em professores do ensino municipal: prevalência e fatores de risco. Rev Bras Otorrinolaringol. 2003; 69(6):807-12.

6. Consenso Nacional Sobre Voz Profissional. [homepage na internet] 2007 [acesso em 14 maio 2007]. Disponível em: URL: http://www. saudeetrabalho.com.br/t-disfonia.php.

7. Sataloff R. Profissional voice: the science and art of clinical care. 2. ed. San Diego- London. Singular Publishing Group Inc.; 1997.

8. Behlau M. Voz: o livro do especialista. Vol 1. Rio de Janeiro: Revinter; 2001. 348p.

9. Simões M, Latorre MRDO. Alteração vocal em professores: uma revisão. J Bras Fonoaudiol. 2002; 3(11):127-34.

10. Mattiske JA, Oates JM, Greenwood KM. Vocal problems among teachers: a review of prevalence, causes, prevention, and treatment. J Voice. 1998; 12(4):489-99.

11. Simberg S, Sala E, Ronnemaa AM. A comparison of the prevalence of vocal symptoms among teacher students and other university students. $\mathrm{J}$ Voice. 2004; 18(3):363-8.

12. Goulart BNG. Contribuição da epidemiologia para a pesquisa e atuação clínica em fonoaudiologia. Fono atual. 2002; 5(21):60-3.

13. Ortiz E, Lima EA, Costa EA. Saúde vocal de professores da rede municipal de ensino da cidade do interior de São Paulo. Rev Bras Med Trabalho. 2004; 2(4):263-6.

14. Tiveron SM. Distúrbio da voz relacionado ao trabalho. [homepage na internet] Saúde e trabalho. [acesso em 14 julho 2007] Disponível em: http:// www.saudeetrabalho.com.br.

15. Servilha EAM. Estresse em professores universitários na área de fonoaudiologia. Rev Ciênc Méd. 2005; 14(1):43-52.

16. Salas SWA, Centeno HJ, Landa CE, Amaya CJM, Benites GMR. Prevalência de disfonia en profesores del distrito de Pampas, Tayacaja, Huancavelica. Rev Med Hered. 2004; 15(3):125-30. 17. Gonçalves CGO, Penteado RZ, Silvério KCA. Fonoaudiologia e saúde do trabalhador: a questão da saúde vocal do professor. Saúde em Revista. 2005; 7(15):45-51.

18. Ferreira LP, Giannini SPP, Figueira S, Silva EE, Karmann DF, Souza TM. Condições de produção vocal de professores da prefeitura do município de São Paulo. Dist Comun. 2003; 14(2):275-307.

19. Delcor NS, Araújo TM, Reis EJF, Porto LA, Carvalho FM, Silva MO, Barbalho L, et al. Condições de trabalho e saúde dos professores da rede particular de ensino de Vitória da Conquista, Bahia, Brasil. Cad Saúde Pública. 2004; 20(1):187-96.

20. Grillo MHMM, Penteado RZ. Impacto da voz na qualidade de vida de professore(a)s do ensino fundamental. Pró-Fono. 2005; 17(3):321-30.

21. Stemple JC. Voice therapy clinical studies. St. Louis: Mosby Year Book; 1993. p. 155-71.

22. lqueda APD. Auto-percepção da voz e interferências de problemas vocais: um estudo com professores da rede municipal de Ribeirão Preto, SP. [dissertação] Ribeirão Preto (SP): Universidade de São Paulo; 2006.

23. Servilha EAM, Pereira PM. Condições de trabalho, saúde e voz em professores universitários. Rev. Ciênc Méd. 2008; 17(1):21-31.

24. Penteado RZ, Pereira IMTB. Avaliação do impacto da voz na qualidade de vida de professores. Rev Soc Bras Fonoaudiol. 2003; 8(2):19-28.

25. Assembleia Legislativa do Estado do Rio de Janeiro. Estatuto dos Funcionários Civis Públicos. [homepage na internet] [acesso em 15 set 2007] Disponível em: URL: http://www.alerj.rj.com.

26. Mitcheel AS. The professional speaking voice. In: Benninger MS, Jacobson BH, Johnson AF. Voice arts medicine: the care and prevention of professional voice disorders. New York: Theme Medical Publishers; 1994. p. 169-76.

27. Dragone MLS, Sichirolli S, Reis R, Behlau M. O desgaste vocal do professor: um estudo longitudinal. Rev Soc Bras Fonoaudiol. 1999; 3(5):50-6.

28. Carvalho MMB. O professor: um profissional, sua saúde e a educação em saúde na escola. [tese] São Paulo (SP): Universidade de São Paulo; 1995. 29. Barreto MASC. Professores/operadores do direito: sua consciência vocal. J Bras Fonoaudiol. 2003; 4(17):261-7.

30. Branco AB, Romariz MS. Doenças das cordas vocais e sua relação com o trabalho. Rev Comun Ciênc Saúde. 2006; 17(1):37-45.

31. Lima FB. Fatores contribuintes para o afastamento dos professores dos seus postos de trabalho, atuantes em escolas públicas municipais localizadas na região Sudeste. [dissertação] Rio 
de Janeiro (RJ): Universidade do Estado do Rio de Janeiro; 2004.

32. Medeiros AM, Barreto SM, Assunção AA. Professores afastados da docência por disfonia: 0 caso de Belo Horizonte. Cad Saúde Colet. 2006; 14(4):615-24.
33. Morin E. Ciência com consciência. 6. ed. São Paulo: Bertrand Brasil; 2002. 344p

34. Simberg S, Sala E, Vehmas K, Laine A. Changes in the prevalence of vocal symptoms among teachers during a twelve-year period. J Voice. 2005; 19(1):95-102.

RECEBIDO EM: 12/08/2008

ACEITO EM: 25/09/2009

Endereço para correspondência:

Lúcia Cristina Fernandes Antunes Provenzano

Rua Fábio da Luz, 244 casa 08

Rio de Janeiro - RJ

CEP: 20720-350

E-mail: luciaprovenzano@yahoo.com.br 